\title{
Explicações assimétricas para a desconfiança em partidos políticos no Brasil
}

Eduardo Alves Lazzari

\section{Introdução}

Por que os brasileiros não confiam em partidos políticos? Mobilizando as hipóteses elencadas pela literatura, o presente artigo visa responder a essa pergunta utilizando um survey realizado e aplicado pelo Núcleo de Pesquisas em Políticas Públicas da Universidade de São Paulo (Nupps/USP) em 2014. Ainda que o país apresente um padrão similar ao de países europeus no apoio a diferentes dimensões de um regime democrático (Norris, 2011), o baixo apoio a partidos registrado no caso brasileiro - aproximadamente $2 \%$ da amostra utilizada disse ter muita confiança em partidos - exige uma melhor compreensão desse fenômeno, justificando o esforço empreendido aqui. Assim, a próxima seção, "A confiança na representação política", desenvolve o argumento que explica a escolha da confiança como atitude-chave para compreender o apoio do eleitorado a partidos políticos, partindo da premissa de que as especificidades da relação entre representantes e representados fazem com que a confiança seja uma atitude moderadora e inata nessa relação. Em seguida, apresentamos os "Marcos teóricos e os condicionantes da confiança", em que trabalhamos o eixo que distingue modelos culturalistas e racionalistas. Na sequência, abordamos a "Operacionalização e desenho de pesquisa", em que tratamos das variáveis que são mobilizadas para testar as hipóteses apresentadas. Posteriormente, relatamos os "Resultados" coletados a partir de regressões logísticas ordinais e as "Considerações finais".

\section{A confiança na representação política}

O objetivo deste artigo é claro. Deseja-se investigar os condicionantes da confiança em partidos políticos no Brasil, à luz de variáveis que a literatura da área convencionou chamar ou de culturalistas ou de racionalistas. Em suma, sua pergunta é: por que os brasileiros não confiam em partidos? A análise do tema se faz premente por três razões.

Em primeiro lugar, o funcionamento do regime democrático em sua forma representativa conserva uma especificidade que pauta a relação entre representantes e representados pela confiança ou pela desconfiança. Entendendo confiança, assim como faz Sztompka (1999), como a crença de um indivíduo "A" de que outro indivíduo ou entidade 
" $B$ " vá se comportar de determinada maneira, em que " $A$ " assume o risco da imprevisibilidade das ações de "B", já que estas fogem a seu controle, a relação entre representantes e representados, ou partidos e eleitores, não possui nenhum mecanismo que produza, necessariamente, convergência entre as expectativas de " $A$ " e as ações de "B". De modo que, se admitirmos a definição de Hardin $(1999)^{1}$ de confiança, há a possibilidade de que os partidos não encapsulem os interesses de eleitores. Com efeito, criam-se as condições para que a confiança seja uma forma de moderar a relação entre partidos e eleitores, que é informal, uma vez que as eleições se encerram e que os eleitores não controlam as ações dos eleitos.

Dificilmente pode-se dizer que alguma perspectiva teórica pressupõe uma tendência natural de coincidência dos interesses de eleitores e ações de partidos e representantes. Nas reflexões sobre representação que foram travadas entre antifederalistas e federalistas após a Convenção de Filadélfia nos debates sobre a ratificação da Constituição americana, os primeiros defendiam a perspectiva de que o mandato do representante fosse "imperativo", isto é, devesse fidedignamente refletir a visão daqueles que ele representa. Isso seria atingido pela seleção de representantes advindos de todas as classes, ocupações ou níveis sociais, eliminando qualquer tipo de critério de renda, nacional ou regional, que determinasse quem poderia e quem não poderia ser eleito para qualquer assembleia.

Por outro lado, para os federalistas, o representante deveria fazer seu próprio julgamento, ainda que a partir dos interesses dos representados, mas com uma avaliação própria de como seus interesses seriam encaminhados de forma mais adequada (Manin, 1995). Assim, garantindo que a totalidade do eleitorado fizesse parte da seleção desses representantes, seria formado um corpo representativo da sociedade e cioso de seus interesses.

De todo modo, seja eliminando qualquer tipo de critério para a ampliação do direito de ser eleito, como preconizavam os antifederalistas, seja mantendo "universal" apenas o direito de eleger, como se posicionaram os federalistas, nenhuma perspectiva assegurava que a ação dos representantes levaria, ao fim e ao cabo, ao encapsulamento dos interesses dos representados, mas apenas à relativa responsividade. Por um lado, os mecanismos escolhidos pelos antifederalistas somente pressupunham que a simples seleção de representantes no seio de uma determinada corporação seria suficiente para sua representação fidedigna e consequente manutenção da confiança; indubitavelmente um mecanismo incapaz de mitigar o risco de que as ações daquele que é investido de confiança fujam do controle daquele que confia. Por outro lado, entre os federalistas, há uma abertura explícita à liberdade do representante em, ocasionalmente, encaminhar os interesses dos representados de uma forma que, para ele, parecesse a melhor. Logo, a

\footnotetext{
${ }^{1}$ No original em inglês: "To say that I trust you with respect to some matter means that I have reason to expect you to act in my interest with respect to that matter because you have good reasons to do so, reasons that are grounded in my interest. In other words, to say that I trust you means I have reason to expect you to act, for your own reasons, as my agent with respect to the relevant matter. Your interest encapsulates my interest" (Hardin, 1999, p. 26).
} 
EXPLICAÇÕES ASSIMÉTRICAS PARA A DESCONFIANÇA EM PARTIDOS POLÍTICOS NO BRASIL

confiança seria um componente da relação entre representados e representantes, qualquer que fosse o lado vencedor do debate americano.

Mesmo se recorrermos a Mill (2006) e ao mecanismo proposto de representação proporcional, tem-se que a composição das assembleias seria mais próxima àquela que se observa na sociedade, porém, a semelhança que se teria entre assembleia representativa e sociedade, isto é, num entendimento da representação semelhante à representação descritiva (Pitkin, 1972), não implica que os representados teriam controle sobre as ações dos representantes, tampouco meios de obtê-lo.

Para a perspectiva rousseauniana, sequer existiria a possibilidade de representantes atenderem aos interesses de representados, já que nenhum indivíduo é capaz de representar os interesses de outro, sem que este esteja presente. Para a perspectiva hobbesiana, essa representação é uma procuração que fornece total liberdade ao representante para agir como bem entende. No pensamento marxista, ainda que não seja uma reflexão sobre a representação per se, esta às vezes se faz desnecessária quando a classe proletária toma consciência de seus interesses de classe, mas é necessária enquanto isso não acontece. Nesse caso os representantes da classe operária devem agir como vanguarda, a despeito dos interesses da classe proletária (Kinzo, 1980; Urbinati, 2006; Lavalle, Houtzager e Castello, 2006).

Ademais, segundo Manin (1995), não seria proveitoso ao funcionamento do regime democrático haver normas institucionais, como o que chama de mandato imperativo, que produzissem, necessariamente, a convergência entre os interesses dos eleitores e as ações dos partidos, quer seja na representação por prestação de contas ou na representação por mandato (Manin, Przeworski e Stokes, 2006), eliminando a independência parcial que os representantes conservam em relação aos representados no exercício de seu mandato.

Se os mecanismos de seleção de representantes não são eficazes para que os representados controlem os representantes e inexistem instituições que os condicionem, a ponto de os representados definirem o curso de ação dos representantes, temos os fatores que Sztompka (1999) lista como elementares numa relação de confiança, a saber, descontrole da ação daquele que confia naquele que é objeto de confiança, já que este conserva certa liberdade, e risco que corre aquele que confia em alguém, afinal, seus interesses podem não ser atendidos.

Por essa razão Sztompka (1999) afirma que o regime democrático institucionalizou a desconfiança através de várias instituições democráticas, tais como a separação de poderes e o próprio sufrágio, na perspectiva de que os atores políticos violarão normas, deturparão suas funções e frustrarão as expectativas dos eleitores.

Em segundo lugar, a confiança em partidos é especialmente importante por serem estes instituições representativas fundamentais num regime democrático. Os partidos resolvem questões de seleção de líderes na sociedade, formação de maiorias parlamentares, controle burocrático, mobilização do eleitorado, formação e institucionalização de políticas públicas, entre tantas outras. Caso profunda desconfiança em partidos engendre distanciamento entre partidos e eleitorado - algo que é apontado 
como sintoma da crise de partidos (Dalton e Wattenberg, 2000) - ter-se-ia o insulamento de partidos políticos no Estado, um mecanismo já descrito por Katz e Mair (1994), comprometendo a renovação de quadros partidários e a mobilização do eleitorado, e onerando o Estado, o qual seria transformado numa organização institucionalizada de suporte, como apontam esses autores.

Por fim, em terceiro lugar, ainda que esta não seja uma análise longitudinal, sendo inviável, portanto, inferir sobre os fatores que afetarão ao longo do tempo a atitude em destaque, o estudo se faz necessário pelo crescimento da desconfiança em partidos políticos registrado em uma série de estudos, no Brasil e internacionalmente (Norris, 1999; Moisés e Meneguello, 2013). Como mostramos adiante, a confiança investida em partidos políticos no Brasil engloba em torno de $2 \%$ da população brasileira, numa amostra de 2 mil respondentes ${ }^{2}$. Investigar e compreender os fatores da desconfiança em partidos é, portanto, uma maneira de acessar a dinâmica representativa do regime democrático brasileiro, em outras palavras, a avaliação do eleitorado sobre os partidos em sua função representativa. Agora, uma vez listadas as justificativas do estudo dessa atitude, é preciso detalhar os fatores que a afetariam, tarefa empreendida na seção seguinte.

\section{Marcos teóricos e os condicionantes da confiança}

Dois marcos teóricos que orientam a literatura na área são os trabalhos de Easton (1975) e Norris (1999). A importância da primeira publicação reside no fato de que, ao diferenciar tipos de apoio, o autor lançou as bases para dois modelos diferentes que explicam o apoio político dado ao Estado ou a outras instituições democráticas. A segunda obra tem clara importância ao ilustrar que o apoio político é multidimensional. Desse modo, desconfiar de partidos políticos, por exemplo, não representa atitude antidemocrática ou autoritária, ao contrário, demonstraria, em alguns casos, um ressentimento que busca o aprimoramento das instituições democráticas.

Easton (1975) distingue dois tipos de apoio: o difuso e o específico. Faz-se necessário explicitar que o autor entende como apoio uma orientação favorável ou negativa de uma pessoa em relação a um objeto. A distinção entre tipos de apoio é importante, pois a existência contínua de atitudes negativas em relação à democracia, ao mesmo tempo em que esta se mantém como único regime político viável, indica que certo apoio, o específico, se refere à performance do regime, enquanto o outro, o difuso, se refere à legitimidade do regime, segundo o autor. Desse modo, ele lançou as bases, inclusive, para a argumentação de Norris (1999), tratada adiante.

Apoio específico seria o produto da satisfação obtida por eleitores quanto a decisões, políticas e resultados apresentados pelo regime. Esse apoio seria uma resposta, uma reação "indiretamente relevante" (Easton, 1975, p. 437) para a sustentação do regime e da comunidade política. Em contrapartida, o apoio difuso seria um apoio abstrato

\footnotetext{
2 Esse número se refere à pesquisa do Nupps aplicada em 2014, pós-manifestações de 2013 , sendo $2 \%$ o contingente que depositou "muita confiança" nessas instituições. Maiores detalhes são apresentados adiante.
} 
ante aquilo que o objeto, a autoridade ou a entidade em questão representa. $\mathrm{O}$ apoio específico é o que deriva da percepção da performance do regime, ele é sensível e suscetível a variações de curto prazo; o apoio difuso é mais durável ou estável que o específico. Por essas características, ele seria mais importante para a estabilidade do regime, sendo suas fontes o processo de socialização do eleitor desde sua infância até a idade adulta e a experiência direta.

A centralidade da obra está no lançamento das fundações dos modelos racionalistas e culturalistas. Por um lado, se o apoio específico se refere à performance do regime, é plausível supor que a avaliação que se faz dela também vá afetar a confiança que se tem em suas autoridades e instituições, considerando seja a avaliação das políticas públicas apresentadas pelo Estado, seja o cumprimento de princípios democráticos, como o império da lei. Por outro lado, se o apoio difuso é afetado pela socialização, variáveis que acessem diferenças individuais como confiança interpessoal, renda e escolaridade também são relevantes para a confiança em instituições representativas. Eis os centros dos modelos racionalistas e culturalistas, respectivamente.

Antes de avançarmos, é fundamental salientar que, se apoio específico e apoio difuso têm uma interação, é preciso incorporar as variáveis de ambos os modelos para precisamente mensurar o efeito destas sobre a confiança em partidos políticos ou qualquer outra atitude da opinião pública. Lançar mão apenas de variáveis racionalistas impossibilitaria a explicação de por que regiões e continentes apresentam, sistematicamente, diferenças no nível de confiança, sugerindo a presença de fatores culturais. Além disso, mobilizar apenas variáveis culturalistas criaria dificuldades na compreensão de por que todas as comunidades políticas apresentam oscilações na trajetória de seus indicadores atitudinais num curto espaço de tempo, como é demonstrado empiricamente por Norris (2011), sugerindo a presença de fatores racionalistas.

Norris (1999), por sua vez, parte da distinção feita por Easton (1975) e supõe que existam cinco dimensões de apoio, em outras palavras, cinco dimensões do regime democrático que são objeto de apoio. A primeira - e mais abstrata - seria a comunidade política. Nesse caso, o membro de uma comunidade pode manifestar seu apoio indicando que se sente parte desse grupo.

A segunda seria o regime democrático em si, seus princípios, ou seja, a avaliação do respondente de que o regime democrático é o melhor, o mais justo ou superior a outros regimes. Em seguida, emerge a avaliação da performance do regime, uma avaliação acerca de seu funcionamento. Por fim, as duas últimas dimensões são as instituições do regime, como partidos políticos, e as autoridades do regime. Indo da primeira para a quinta e última dimensão, mais nos aproximamos do apoio específico. Consequentemente, o apoio à comunidade política indicaria a dimensão mais próxima do apoio difuso.

A divisão proposta por Norris (1999) é importante, pois demonstra que cidadãos podem manifestar sua insatisfação com partidos políticos, sem condenarem o regime por completo. Isso é empiricamente investigado em seu livro, no qual se ilustra a coexistência de altos níveis de apoio à comunidade política e aos princípios do regime democrático, ao 
mesmo tempo em que existem avaliações erráticas em relação à performance do regime e às autoridades, com uma tendência decrescente de confiança nas instituições representativas, como partidos políticos. O que se vê em sua análise é que não só essas dimensões de apoio são conceitualmente diferentes, como também elas são empiricamente verificáveis. Assim, mesmo em países como o Brasil, há um forte apoio à comunidade política e aos princípios do regime democrático, uma avaliação não tão positiva da performance do regime e pouquíssimo apoio aos partidos ou reduzida deferência às autoridades. Os dois marcos teóricos de que nos utilizamos neste artigo permitem que se foque, em primeiro lugar, em fatores de diferentes naturezas para o apoio e a confiança investida pelo eleitorado e, em segundo lugar, especificamente no apoio a partidos políticos ${ }^{3}$.

Nos modelos racionalistas há um claro enfoque na efetivação do apoio específico (Easton, 1975). Conforme o autor, se o apoio específico varia de acordo com o desempenho do regime, variáveis que captam a situação econômica ou a performance de instituições ambas influenciadas pelos partidos, os quais são responsáveis pelas instituições -, por exemplo, seriam as melhores alternativas para explicar o nível de confiança em partidos políticos.

Nessa vertente, testam-se duas hipóteses, grosso modo. A primeira é de que a mídia afetaria a confiança em partidos políticos. Tomemos como exemplo o trabalho de Duch e Stevenson (2008). Ainda que seu objeto de estudo - o voto econômico - seja diferente, os autores investigam duas hipóteses relacionadas à mídia. A primeira, de que a mídia forneceria informações sobre o desempenho econômico de sua localidade, informando os eleitores; e a segunda, de que os eleitores absorveriam essas informações, transformando sua avaliação sobre o cenário econômico e, indiretamente, afetando as eleições. Se esse é o caso, faz-se necessário refletir sobre a possibilidade de que a imprensa possa afetar não só o voto, mas também diferentes dimensões de apoio à democracia, entre elas, a confiança que partidos inspirariam no eleitorado.

Esse é o raciocínio utilizado na hipótese informacional. Grosso modo, a passagem da democracia de partido para a democracia de público significou a crescente irrelevância da mídia partidária (Manin, 1995). A opinião pública passou a buscar informação em veículos ditos independentes, abrindo espaço para um tom mais crítico em relação ao desempenho do sistema político.

O enfoque se daria muito mais sobre os aspectos negativos do governo do que sobre os seus pontos positivos. Dado o distanciamento entre cidadãos e partidos políticos (Dalton e Wattenberg, 2000) e a migração para uma mídia apartidária, essa tese se torna

\footnotetext{
3 Merece destaque ainda o trabalho de Booth e Seligson (2009). Os autores empreendem esforços em investigar, empiricamente, a percepção de diferentes dimensões de apoio à democracia no contexto latinoamericano, mais especificamente em oito países: Colômbia, Costa Rica, El Salvador, Guatemala, Honduras, México, Nicarágua e Panamá. Como os autores demonstram, esses países apresentam um padrão de apoio a essas dimensões similar ao observado em países desenvolvidos, justificando inclusive a realização de um artigo como este, que se debruça, especificamente, sobre uma dessas dimensões, a confiança em partidos, no Brasil.
} 
particularmente importante, já que a principal fonte de informações sobre política seriam aqueles veículos interessados, justamente, no constrangimento de autoridades e partidos políticos. Porto (2000) se insere entre aqueles que afirmam que a mídia fomentaria a desconfiança em políticos e na política como um todo, chegando a criar obstáculos à consolidação do regime democrático brasileiro, uma perspectiva semelhante à de Chaia e Teixeira (2001). Assim, a hipótese informacional se insere num modelo racionalista, pois a avaliação da performance do regime é "deturpada"4 pela mídia.

A segunda hipótese, dentro desse modelo, é muito mais próxima do cerne do argumento do apoio específico. A performance do regime democrático seria decisiva para a confiança em partidos políticos, pois essas instituições seriam as principais responsáveis pela qualidade dessa performance. Seriam três os tipos de performance que afetariam a confiança em partidos.

A primeira seria a performance procedimental, sujeita à avaliação que se faz do funcionamento dos marcos políticos do regime democrático. Como exemplos temos: a isonomia de todos perante a lei - o chamado império da lei -, a lisura das eleições e ainda a avaliação que se faz da corrupção. A segunda, chamada performance econômica, estaria próxima do desempenho da economia, ou seja, a confiança variaria de acordo com a competência das instituições representativas em entregar um bom desempenho econômico. Por fim, haveria a performance institucional, que se assentaria sobre a premissa de que instituições diferentes apresentam desempenhos diferentes. Tomemos como exemplo os modelos ditos consociativos (Lijphart, 2003). Em tese, esses modelos estariam normalmente associados à maior inclusão, já que facilitariam a participação de minorias em arenas representativas, produzindo mais "vencedores". Desse modo os interesses de uma quantidade maior de pessoas seriam atendidos, aumentando a confiança em partidos políticos, diferentemente de modelos tidos como majoritários.

A despeito de generalizações acerca do comportamento dessas instituições, como as que afirmam que arranjos federativos funcionariam de maneira semelhante entre todo o diverso grupo de Estados com esse formato, bem como que funcionariam de maneira fundamentalmente distinta da dos países unitários, o teste de tal hipótese é comprometido num artigo que não é comparado, como este. A racionalidade por trás desses questionamentos é de que diferentes instituições engendram uma quantidade diferente de "vencedores", isto é, eleitores que se sentem "vitoriosos" após a realização de uma disputa eleitoral. Por isso, em estudos de caso, investiga-se se manifestar alguma proximidade com o partido que ocupa a presidência nacional poderia estar associada a uma maior confiança em partidos em geral. O argumento se enquadra numa hipótese de avaliação institucional e num modelo racionalista, pois se faria uma avaliação da performance de partidos políticos em geral, que, por sua vez, é caudatária da relação que se estabelece entre o indivíduo e o partido político de sua preferência, no caso, aquele que ocupava o Executivo nacional quando da aplicação do questionário que embasa este artigo, o Partido

\footnotetext{
4 Muito embora o termo "deturpada" se refira à influência da mídia sobre a avaliação dos cidadãos, qualquer que ela seja.
} 
dos Trabalhadores (PT). Assim, a avaliação da performance do regime é enviesada positivamente pela identificação do respondente em relação ao incumbente, já que as decisões tomadas por este têm probabilidade maior de se aproximar das preferências de seus simpatizantes, contribuindo para uma maior confiança.

É interessante notar que Carneiro e Moisés (2015), utilizando a onda de 2011 do consórcio Latinobarômetro, encontram que ser apartidário ou partidário de outro partido que não aquele que ocupa a presidência nacional aumenta a chance de desconfiar de partidos políticos. Isso também acontece em avaliações negativas da economia (Moisés e Meneguello, 2013), já lançando, portanto, elementos para supor que, no caso brasileiro, fatores racionalistas vão interferir na atitude em foco neste artigo.

Caudatários do apoio difuso de Easton (1975), por ser este resiliente ao longo do tempo, e também da produção em Cultura Política, os modelos culturalistas têm como premissa a tese de que certos valores consolidados numa comunidade vão determinar a conduta e as atitudes da opinião pública em relação às instituições representativas e ao regime democrático em geral.

Sob outra perspectiva, se as causas da desconfiança nos modelos racionalistas estão no Estado, isto é, aqueles responsáveis pelos outcomes do sistema político, em que a confiança é uma reação às decisões e ações dos representantes, nos modelos culturalistas, a causa da desconfiança ou a origem da confiança está em parte na própria opinião pública, em seus valores e atitudes.

Sendo assim, existem dois argumentos que estariam conformados num modelo culturalista: o da socialização e o da confiança interpessoal ${ }^{5}$. Sucintamente, o modelo de socialização aponta que certas características sociais estariam inclinadas a engendrar menor ou maior confiança. Como essa tendência seria definida histórica e socialmente, cabe analisá-la empiricamente, se existir, caso a caso, inviabilizando inferências prematuras dos efeitos de escolaridade, renda, gênero e idade sobre a confiança ${ }^{6}$.

$\mathrm{O}$ argumento da confiança interpessoal está contido no conceito mais abrangente de capital social, elaborado por Putnam (1995). Sua premissa é de que a confiança em pessoas estranhas ao respondente na sociedade é indicativa da confiança que partidos inspiram, tendo, portanto, um efeito intuitivo. Pessoas que confiam mais nos membros de sua sociedade, ainda que desconhecidos, teriam maior confiança em partidos, ainda que não seja possível estabelecer um mecanismo causal claro entre os dois tipos de confiança. Segundo o autor, a confiança entre os indivíduos de uma mesma sociedade é fundamental para, em primeiro lugar, o associativismo e, em segundo, para o vigor da democracia. A preocupação do autor emerge a partir da constatação de que essa confiança entre estranhos estaria diminuindo nos EUA. Enquanto nas décadas de 1950 e 1960, por

\footnotetext{
${ }^{5}$ Deve-se frisar que a hipótese pós-materialista (Inglehart e Flanagan, 1987) é outra que merece destaque nesse campo, no entanto, o questionário utilizado não possui perguntas que permitam investigá-la, justificando sua ausência.

${ }^{6}$ Sem dúvida o fator racial pode ser incluído no rol de elementos pertencentes à hipótese da socialização. Contudo, o survey utilizado não aplicou uma pergunta que captasse a raça do respondente, fazendo com que a questão racial não seja tratada neste artigo.
} 
EXPLICAÇÕES ASSIMÉTRICAS PARA A DESCONFIANÇA EM PARTIDOS POLÍTICOS NO BRASIL

exemplo, os cidadãos americanos participavam ativamente em diversas associações, atualmente estes são caracterizados pela apatia e pelo distanciamento em relação a esse tipo de associação. Norris (2011) se interessou pelo tema e investigou o impacto da confiança interpessoal sobre as aspirações democráticas e o déficit desse regime ${ }^{7}$. A autora encontrou um efeito positivo dessa variável sobre as aspirações democráticas e o déficit que os respondentes manifestam. Desse modo, o argumento sugere que a confiança interpessoal afeta negativamente a probabilidade de desconfiar de partidos políticos. Agora, com os marcos teóricos descritos e as hipóteses com que trabalhamos apresentadas, resta analisar como esses fatores, conjuntamente, afetam a confiança nos partidos no Brasil.

\section{Operacionalização e desenho de pesquisa}

Os dados deste artigo são derivados de um questionário aplicado e coletado em 2014, num projeto conduzido pelo Núcleo de Pesquisa de Políticas Públicas da USP (Nupps). No caso, foram entrevistadas 2 mil pessoas, constituindo uma amostra representativa da população brasileira. O banco originado dessa coleta segue um esforço da academia brasileira de registrar a opinião pública via surveys, tal como o Estudo Eleitoral Brasileiro (Eseb), organizado pelo Centro de Estudos de Opinião Pública, da Unicamp.

Além disso, é fundamental frisar o contexto no qual esses dados foram coletados. A pesquisa foi feita no primeiro trimestre de 2014, sendo, portanto, posterior às manifestações de junho de 2013, caracterizadas por, entre outros fatores, forte rejeição a partidos políticos. Em outras palavras, o presente artigo capta o quadro generalizado de insatisfação em relação aos partidos políticos que marcou as manifestações daquele ano. Por conseguinte, é de esperar que os dados reflitam o ápice dessa insatisfação, em comparação a surveys anteriores de natureza similar. A conjuntura é, portanto, essencial para analisar os dados que são revelados neste artigo e explicar, parcialmente, os elevados índices de desconfiança.

\footnotetext{
7 Por déficit do regime, a autora entende a diferença entre as expectativas dos respondentes com a democracia e as suas insatisfações, em que, quanto maior as últimas em relação às primeiras, maior o déficit democrático.
} 
Tabela 1

Confiança em instituições (\%)

\begin{tabular}{|l|c|c|c|c|}
\hline Instituição & Muita & Alguma & Pouca & Nenhuma \\
\hline Bombeiros & 45,19 & 33,72 & 16,13 & 4,96 \\
\hline Igreja & 23,48 & 40,64 & 25,19 & 10,69 \\
\hline F. Armadas & 19,22 & 35,66 & 29,19 & 15,93 \\
\hline Judiciário & 9,67 & 27,99 & 40,79 & 21,56 \\
\hline Presidente & 8,22 & 29,29 & 36,86 & 25,63 \\
\hline Mov. sociais & 7,63 & 30,86 & 41,76 & 19,75 \\
\hline Polícia & 6,76 & 25,89 & 42,41 & 24,94 \\
\hline Televisão & 6,22 & 32,6 & 40,32 & 20,86 \\
\hline Leis & 4,93 & 24,33 & 42,38 & 28,36 \\
\hline Governo & 4,77 & 22,84 & 41,06 & 31,33 \\
\hline Congresso & 4,67 & 19,69 & 43,43 & 32,22 \\
\hline Sindicatos & 4,16 & 22,09 & 42,89 & 30,87 \\
\hline Empresários & 3,52 & 22,02 & 41,13 & 33,33 \\
\hline Partidos & 2,66 & 12,65 & 38,96 & 45,73 \\
\hline
\end{tabular}

Fonte: Elaboração própria com base em Nupps (2014).

Em geral, pode-se observar que são poucas as instituições que gozam de ampla confiança da sociedade brasileira. O questionário apresentava aos respondentes o seguinte enunciado: "Vou citar alguns órgãos públicos e instituições e gostaria de saber qual é o grau de confiança que o(a) Sr(a). tem em cada um deles. Você diria que tem nenhuma confiança, pouca confiança, alguma confiança ou muita confiança em [instituição]?".

À exceção da igreja, das Forças Armadas e dos bombeiros, nenhuma outra instituição é objeto de muita confiança por mais de $10 \%$ da população. Os partidos são os que têm o menor contingente com muita confiança $(2,66 \%)$, bem como o menor contingente com alguma confiança $(12,65 \%)$ e a maior parcela da população com nenhuma confiança $(45,73 \%)$.

Nos testes subsequentes, a variável dependente terá três níveis. O primeiro engloba os indivíduos com alguma e muita confiança, as quais integram a categoria razoável confiança. Em seguida tem-se o nível de pouca confiança e, por fim, o último nível, nenhuma confiança. Tal escolha foi feita pela baixíssima quantidade de indivíduos com muita confiança em partidos políticos. Sendo 2,66\% da amostra, há, num universo de 2 mil pessoas, apenas $56 \mathrm{com}$ tal nível de confiança. Ao fundir as categorias de muita e alguma confiança, tenta-se, portanto, mitigar o viés produzido por essa baixa quantidade de respondentes na referida categoria, aumentando a precisão do modelo. Para investigar os fatores determinantes para a confiança em partidos políticos no Brasil, são usadas regressões logísticas ordinais. Como o próprio nome indica, supõe-se que a variável dependente assume diferentes categorias que, entre si, constituem um ordenamento.

A principal diferença produzida por essa escolha são os chamados pontos de corte. $\mathrm{Na}$ Tabela 2, apresentam-se dois pontos de corte. Isso acontece em razão de serem três as categorias que $y$ pode assumir. Logo, o ponto de corte 1 indica o valor que determina, estatisticamente, o intercepto de $y$ igual a 0 , no caso, razoável confiança. Os valores 
EXPLICAÇÕES ASSIMÉTRICAS PARA A DESCONFIANÇA EM PARTIDOS POLÍTICOS NO BRASIL

compreendidos entre os pontos de corte 1 e 2 determinam estatisticamente o intercepto de $y$ igual a 1, pouca confiança. Enfim, o ponto de corte 2 indica o intercepto que determina estatisticamente os valores de $y$ igual a 3 , nenhuma confiança.

Com efeito, a operacionalização proposta e detalhada acima implica que coeficientes positivos indicam um fator que aumenta a probabilidade de se ter nenhuma confiança em partidos políticos, em outras palavras, a probabilidade de desconfiar de partidos políticos. Por outro lado, coeficientes negativos indicam um fator que diminui a probabilidade de desconfiar dessas instituições.

Seguindo-se à operacionalização das variáveis independentes, destacamos em primeiro lugar as variáveis do campo culturalista. A categoria de referência para a variável sexo é a feminina, ou seja, os coeficientes apresentados revelam o impacto de ser homem sobre a desconfiança em partidos, em relação às mulheres. Tratando-se da renda, optouse por dividir os respondentes, conforme o survey, de acordo com suas classes. Isto é, a pesquisa de opinião pública divide os respondentes nas classes $E, D, C 2, C 1, B 2, B 1, A 2$ e $A 1$, da mais pobre para a mais rica. Duas observações merecem ser feitas em relação à renda. Primeiro, a categoria de referência é a classe mais pobre, E, assim, os coeficientes são uma comparação do pertencimento à classe $D$, por exemplo, em relação à classe $E$. Segundo, fundiram-se as classes A2 e A1 em uma única categoria pela reduzida quantidade de pessoas nessas classes, 34 e 3, respectivamente.

A pesquisa também é muito rica no detalhamento de escolaridade, tendo sete níveis, desde os respondentes analfabetos ou com primário incompleto até aqueles com ensino universitário completo. A categoria de referência é composta por analfabetos ou indivíduos com primário incompleto. Idade, por sua vez, conserva sua contagem discreta, variando, na amostra, entre 16 e 83 anos. Como se disse acima, dado que a associação entre variáveis demográficas e desconfiança é construída socialmente, supor que idade, por exemplo, afetaria positivamente a desconfiança é arbitrário, restando verificar essa associação empiricamente.

Ainda pertinente aos modelos culturalistas, estimamos o efeito da presença da confiança interpessoal sobre a desconfiança em partidos políticos. A pesquisa demandava aos respondentes o seguinte questionamento: "Você acha que se pode confiar na maioria das pessoas ou, pelo contrário, que todo cuidado é pouco no trato com os outros?". Essa pergunta se refere aos membros estranhos da sociedade a que pertence o respondente, em vez de parentes ou amigos, de modo que, se o respondente afirmasse que pode confiar na maioria das pessoas, entendeu-se que este tinha confiança interpessoal; se a resposta fosse negativa, o respondente seria pertencente ao grupo daqueles sem confiança interpessoal.

No tocante às variáveis de modelos racionalistas, o efeito da hipótese informacional será acessado a partir do consumo de Jornal Nacional ("Consumo JN"). Perguntou-se ao respondente com que frequência ele assistia, semanalmente, a esse jornal, de uma a seis vezes ou nunca. Argumenta-se que essa pergunta acessa o cerne da hipótese informacional por duas razões. Primeira, boa parte do conteúdo do jornal se refere a temas políticos, 
consequentemente, é plausível supor que, à medida que a frequência de consumo de JN aumenta, maiores são as chances de que a desconfiança em partidos seja afetada, afinal, o respondente teria mais elementos para avaliar os partidos políticos. Segunda, os estudos de Mesquita $(2010,2013)$ já trataram dessa hipótese com essa medida e reconheceram um efeito positivo e importante sobre a satisfação com a democracia, confiança nas Forças Armadas, nos empresários e em outras instituições. Sendo assim, os testes abaixo visam a uma melhor compreensão da aparente contradição entre o efeito negativo esperado da mídia sobre a confiança (Porto, 2000; Chaia e Teixeira, 2001) e os dados apresentados por Mesquita (2010, 2013).

A variável que mensura a avaliação procedimental é o julgamento que se faz da corrupção ao longo do primeiro mandato de Dilma Rousseff (2011-2014). No questionário perguntava-se: "Falando de corrupção e tráfico de influência, no governo da presidente Dilma essas coisas melhoraram, pioraram ou ficaram iguais ao que era antes?". Assim, se a hipótese estiver correta, uma avaliação de que a corrupção melhorou - no sentido que diminuiu - implicará uma menor probabilidade de se ter nenhuma confiança em partidos. A mesma estratégia de operacionalização foi usada no teste da avaliação econômica, em que se acessava o tema da seguinte maneira: "E quanto à situação econômica do Brasil no governo Dilma - desde janeiro de 2011 -, você diria que a situação econômica do país melhorou, piorou ou ficou igual ao que era antes?"; sendo que a categoria de referência em ambos os casos é a avaliação de que a corrupção ou a economia pioraram no período citado.

A última das hipóteses racionalistas trata do efeito institucional. Como se disse, o efeito testado aqui seria a possibilidade de que a identificação com o partido que ocupava a presidência nacional, o PT, produziria algum impacto na confiança em partidos. Logo, dividiu-se a amostra entre aqueles respondentes que afirmaram simpatizar com o PT denominados partidários vencedores - e aqueles que não o fizeram, a partir da pergunta "Desta lista de partidos, de qual você se sente mais próximo em $1^{\circ}$ e $2^{\circ}$ lugar?", ou seja, se o respondente tiver escolhido o PT como partido mais próximo em primeiro ou segundo lugar, este seria enquadrado como partidário vencedor e os demais, como "perdedores". Tomando como referência o último grupo, a expectativa é de que os chamados partidários vencedores tenham menor probabilidade de ter nenhuma confiança em partidos.

\section{Resultados}

Para a investigação das hipóteses elencadas até aqui são executados três modelos. O primeiro inclui as variáveis caras à hipótese de socialização: sexo, classe, escolaridade e idade; e a hipótese remanescente do campo culturalista: confiança interpessoal. 0 segundo modelo analisa, por sua vez, a hipótese informacional e as hipóteses de avaliação procedimental, econômica e institucional, as chamadas hipóteses avaliativas. Por fim, 0 terceiro modelo considera aquelas variáveis tidas como significantes nos modelos 1 e 2 , articulando, por conseguinte, hipóteses dos campos culturalista e racionalista. 
EXPLICAÇÕES ASSIMÉTRICAS PARA A DESCONFIANÇA EM PARTIDOS POLÍTICOS NO BRASIL

Tabela 2

Regressões logísticas ordinais modelos 1, 2 e 3 (erro-padrão - EP)

\begin{tabular}{|c|c|c|c|}
\hline \multirow{2}{*}{ Confiança em partidos (nenhuma confiança) } & Modelo 1 & Modelo 2 & Modelo 3 \\
\hline & $\beta(E P)$ & $\beta(E P)$ & $\beta(E P)$ \\
\hline \multirow{2}{*}{ Masculino } & $-0,049$ & & \\
\hline & $-0,09$ & & \\
\hline \multirow{2}{*}{ Classe D } & $1,029 *$ & & \\
\hline & $-0,42$ & & \\
\hline \multirow{2}{*}{ Classe C2 } & 0,818 & & \\
\hline & $-0,42$ & & \\
\hline \multirow{2}{*}{ Classe C1 } & 0,74 & & \\
\hline & $-0,42$ & & \\
\hline \multirow{2}{*}{ Classe B2 } & $0,866^{*}$ & & \\
\hline & $-0,43$ & & \\
\hline \multirow{2}{*}{ Classe B1 } & $1,043 *$ & & \\
\hline & $-0,45$ & & \\
\hline \multirow{2}{*}{ Classes A2 e A1 } & 0,009 & & \\
\hline & $-0,53$ & & \\
\hline \multirow{2}{*}{ Primário completo } & 0,337 & & \\
\hline & $-0,19$ & & \\
\hline \multirow{2}{*}{ Ginásio incompleto } & 0,239 & & \\
\hline & $-0,17$ & & \\
\hline \multirow{2}{*}{ Ginásio completo } & $0,428 *$ & & \\
\hline & $-0,21$ & & \\
\hline \multirow{2}{*}{ Colégio incompleto } & 0,103 & & \\
\hline & $-0,2$ & & \\
\hline \multirow{2}{*}{ Colégio completo } & 0,128 & & \\
\hline & $-0,17$ & & \\
\hline \multirow{2}{*}{ Universitário incompleto } & $0,526 *$ & & \\
\hline & $-0,25$ & & \\
\hline \multirow{2}{*}{ Universitário completo ou mais } & 0,339 & & \\
\hline & $-0,22$ & & \\
\hline \multirow{2}{*}{ Idade } & 0,00 & & \\
\hline & 0,00 & & \\
\hline \multirow{2}{*}{ Confiança interpessoal } & $-1,111 * * *$ & & $-1,059 * * *$ \\
\hline & $-0,14$ & & $-0,15$ \\
\hline \multirow{2}{*}{ Consumo JN } & & $-0,053^{*}$ & $-0,050 *$ \\
\hline & & $-0,02$ & $-0,02$ \\
\hline \multirow{2}{*}{ Corrupção igual } & & $-0,298 * *$ & $-0,297 * *$ \\
\hline & & $-0,11$ & $-0,11$ \\
\hline \multirow{2}{*}{ Corrupção melhorou } & & $-0,708 * * *$ & $-0,697 * * *$ \\
\hline & & $-0,13$ & $-0,14$ \\
\hline \multirow{2}{*}{ Economia igual } & & $-0,333 * *$ & $-0,336 * *$ \\
\hline & & $-0,12$ & $-0,12$ \\
\hline \multirow{2}{*}{ Economia melhorou } & & $-0,533 * * *$ & $-0,512 * * *$ \\
\hline & & $-0,14$ & $-0,14$ \\
\hline \multirow{2}{*}{ Partidário PT } & & $-0,572 * * *$ & $-0,578 * * *$ \\
\hline & & $-0,10$ & $-0,10$ \\
\hline
\end{tabular}


EDUARDO ALVES LAZZARI

\begin{tabular}{|l|c|c|c|}
\hline \multirow{2}{*}{ Confiança em partidos (nenhuma confiança) } & Modelo 1 & Modelo 2 & Modelo 3 \\
\cline { 2 - 4 } & $\boldsymbol{\beta}$ (EP) & $\boldsymbol{\beta}$ (EP) & $\boldsymbol{\beta}$ (EP) \\
\hline Ponto de Corte 1 & $-0,858$ & $-2,795 * * *$ & $-2,921 * * *$ \\
\cline { 2 - 4 } Constante & $-0,45$ & $-0,14$ & $-0,15$ \\
\hline Ponto de Corte 2 & $1,092 *$ & $-0,776 * * *$ & $-0,853 * * *$ \\
\cline { 2 - 4 } Constante & $-0,45$ & $-0,13$ & $-0,13$ \\
\hline chi $^{2}$ & 88,553 & 161,465 & 213,94 \\
\hline P & $<0,001$ & $<0,001$ & $<0,001$ \\
\hline $\mathrm{N}$ & 1982 & 1897 & 1891 \\
\hline
\end{tabular}

Fonte: Elaboração própria com base em Nupps (2014).

Notas: categoria de referência da variável sexo: feminino; categoria de referência da variável renda: E; categoria de referência da variável escolaridade: analfabeto/primário incompleto; categoria de referência da variável avaliação da corrupção: piorou; categoria de referência da variável avaliação da economia comparada ao ano anterior: pior; categoria de referência da variável partidário do vencedor: não partidário/perdedor; categoria de referência da variável confiança interpessoal: sem confiança interpessoal; $* p<, 05 ; * * p<, 01 ; * * * p .<, 001$.

O primeiro modelo revela que nenhuma das hipóteses de socialização se mostrou importante para a desconfiança em partidos. Isto é, no modelo 1, as classes D, B2 e B1 afetam de maneira significante estatisticamente a probabilidade de não se ter nenhuma confiança em partidos, em relação aos indivíduos da classe E. No entanto, se a renda fosse um fator importante para a desconfiança em partidos, poderia se esperar que existisse uma relação linear da renda, ou seja, quanto maior a renda, menor ou maior a desconfiança em partidos de maneira monotônica. Em outras palavras, não é possível derivar dos resultados encontrados que, conforme a renda cresce, maior ou menor seria a confiança em partidos, pois o efeito está concentrado nas classes D, B2 e B1, na comparação com a classe mais pobre, a E. Ainda sobre renda, é possível observar que todas as classes, à exceção da $\mathrm{A} 2$ e $\mathrm{A} 1$, têm um coeficiente superior a 0 , indicando que as classes que estão nos extremos da distribuição - E, A2 e A1 - têm chances virtualmente iguais de desconfiar de partidos políticos, contribuindo para o argumento de que a renda não é um fator que afeta a desconfiança em partidos.

O mesmo se aplica para o caso de escolaridade, em que mais uma vez a significância estatística ficou concentrada em apenas alguns grupos, inviabilizando inferências que traçam um efeito claro da escolaridade sobre a desconfiança em partidos. Desnecessário dizer que, no primeiro modelo, idade e gênero não apresentam nenhuma significância estatística.

Contudo, recebe-se sem surpresa a dificuldade que essas variáveis culturalistas têm em explicar a desconfiança em partidos. Considerando que os indivíduos com muita ou alguma confiança em partidos chegam a apenas $15 \%$ da amostra, aproximadamente, (Tabela 1), a desconfiança atravessa clivagens etárias e socioeconômicas. Denota-se algo já claro em dados descritivos, a desconfiança em partidos é generalizada.

Ainda referente ao modelo 1 , merece destaque o pronunciado efeito registrado pela confiança interpessoal. Se o respondente tem confiança interpessoal, as chances de 
desconfiar de partidos políticos caem $67 \%{ }^{8}$, conforme previa a teoria. Assim, ainda que as hipóteses de socialização não aparentem estar associadas à desconfiança, a hipótese culturalista remanescente, a de confiança interpessoal, se mostra fundamental para compreender esse fenômeno.

O modelo 2 incorpora, por sua vez, as hipóteses do campo racionalista. Seguindo o mesmo sentido daquele descrito pela literatura, em relação às hipóteses de avaliação procedimental, econômica e institucional, pode-se dizer que, ao avaliar positivamente a evolução da corrupção e a economia e se identificar com o então incumbente do Executivo nacional, as chances de desconfiar de partidos políticos são diminuídas. O mesmo acontece à medida que cresce o consumo do JN. Quanto maior esse consumo, menor a desconfiança em partidos. Os resultados são conservados no modelo 3, que inclui a variável de confiança interpessoal. Por sua vez, avaliar que a corrupção diminuiu, que a economia melhorou ou ser partidário do PT diminui em $51 \%$, $41 \%$ e $44 \%$, respectivamente, as chances de se ter nenhuma confiança em partidos. Diferentemente do que se esperava, o consumo de JN está negativamente associado à desconfiança. A cada unidade de consumo desse jornal, caem em $5 \%$, aproximadamente, as chances de desconfiar de partidos.

Buscando facilitar a interpretação desses resultados, estimamos a probabilidade de se ter nenhuma, pouca ou razoável confiança em partidos políticos, a partir do modelo 3. Esse procedimento ilustra que, a despeito do efeito estatisticamente significante registrado pelo consumo de $\mathrm{JN}$, ele não se converte num efeito substantivo, pois, como se pode observar no Gráfico 1, a probabilidade de se ter nenhuma confiança em partidos políticos se se consome o telejornal seis vezes por semana é estatisticamente igual, considerando os intervalos de confiança, à mesma probabilidade de quando não o se consome, controlando as demais variáveis em suas médias. Os resultados encontrados na investigação dessa hipótese corroboram os encontrados por Mesquita (2010, 2013), em que o consumo desse jornal se mostrou associado a uma diminuição da desconfiança. Ainda que esse método não seja capaz de identificar causalidade entre as variáveis dependente e independente, aponta-se a necessidade de refletir sobre os fatores que levariam o consumo de $\mathrm{JN}$ a mitigar a desconfiança, possibilidade pouco explorada pela literatura.

\footnotetext{
${ }^{8}$ Os coeficientes estimados na Tabela 2 estão no formato logarítmico das chances de desconfiar de partidos políticos a cada unidade alterada na variável independente em análise. No entanto, o valor apresentado na Tabela 2 é de difícil interpretação, de modo que seu valor é convertido em razões de chance. Como o coeficiente de confiança interpessoal no modelo 1 foi igual a -1,111, ao elevá-lo, tem-se 0,329. Sendo uma razão de chance, o valor é subtraído de 1 para estimar essa variação, permitindo sua interpretação. A partir desse momento, os coeficientes serão interpretados e estimados por meio desse procedimento.
} 


\section{Gráfico 1}

Probabilidades dos níveis de confiança - Consumo JN

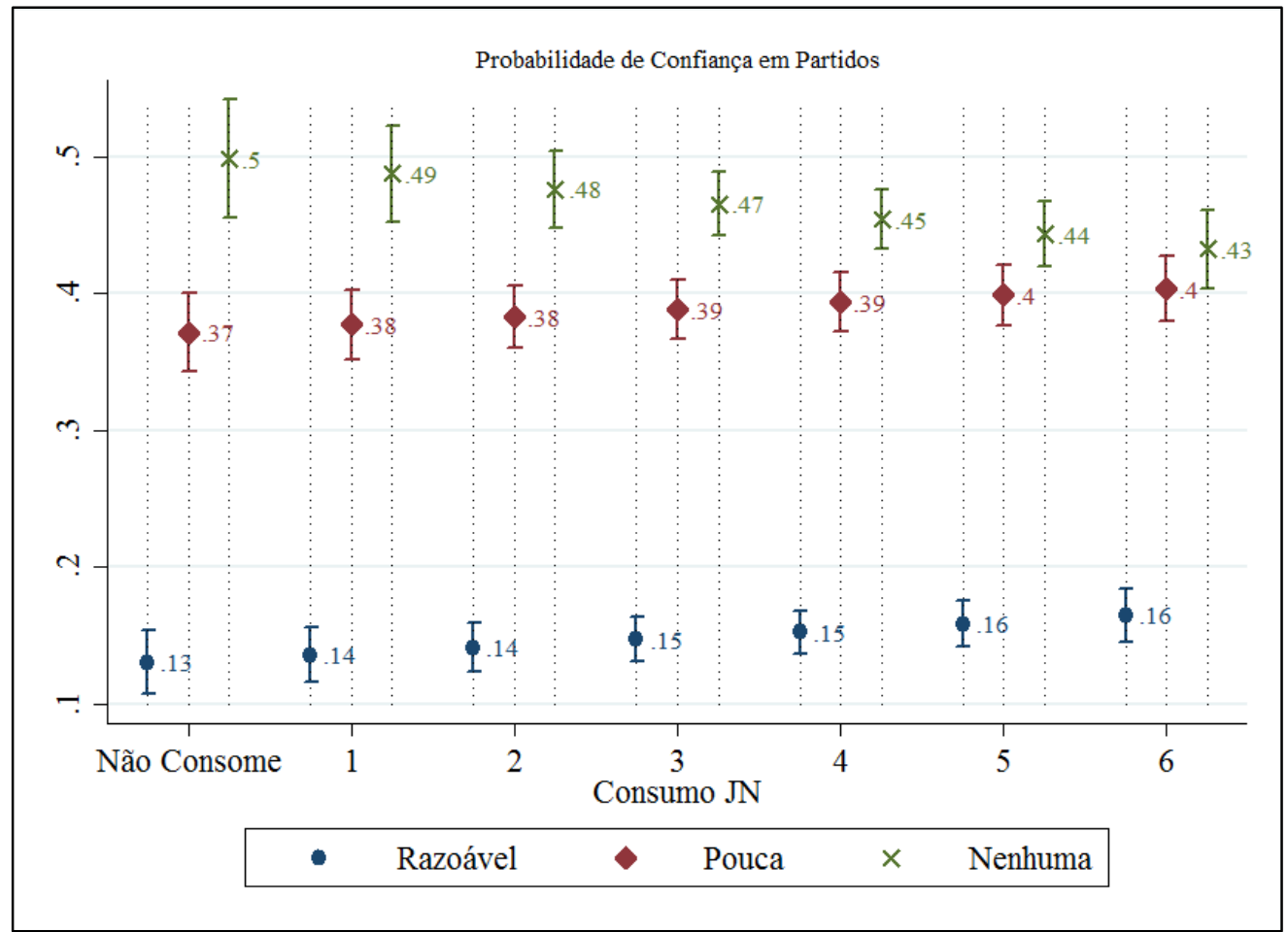

Fonte: Elaboração própria com base em Nupps (2014).

Conforme se argumentou acima, variáveis racionalistas e culturalistas se mostraram relevantes para a diminuição ou o aumento da desconfiança em partidos. Piores avaliações e inexistência de confiança interpessoal contribuem, de maneira inconteste, para o aumento da desconfiança em partidos. No entanto, é preciso investigar se os efeitos que produzem sobre o cultivo, por assim dizer, de confiança são da mesma monta do que estes revelados sobre a desconfiança. Como apontam Clark, Gilligan e Golder (2006), é preciso certificar que as variáveis apontadas não constituam hipóteses assimétricas, em que os efeitos produzidos na presença de $x$, por exemplo, sejam menores ou maiores que aqueles produzidos em sua ausência. Iniciamos tal investigação a partir de testes que avaliam a precisão do modelo e a estimação dos efeitos marginais de cada variável sobre as diferentes categorias da variável dependente.

Por isso se estimou, à luz do terceiro modelo, a probabilidade de o respondente em questão ter nenhuma, pouca ou razoável confiança em partidos políticos. Sendo assim, suponha-se, em relação ao respondente 1, que ele afirmou ter uma avaliação de que a corrupção ficou igual, que a economia piorou, que não era partidário do partido incumbente e que tinha confiança interpessoal. Essas informações eram preenchidas no modelo citado e as probabilidades para cada categoria de $y$ eram calculadas. Se entre estas, a maior probabilidade encontrada fosse de que ele teria pouca confiança em partidos políticos, 
EXPLICAÇÕES ASSIMÉTRICAS PARA A DESCONFIANÇA EM PARTIDOS POLÍTICOS NO BRASIL

entendeu-se que o modelo o apontava como um respondente com pouca confiança nessas instituições. A Tabela 3 simplesmente contingencia esse procedimento com o que foi, de fato, registrado no survey. Assim, a diagonal em negrito dessa tabela mostra para quantos indivíduos o modelo estimou corretamente a atitude do respondente. A expectativa é de que um modelo preciso apresente o maior contingente nessa diagonal.

Tabela 3

Contingenciamento de estimação do modelo e amostra

\begin{tabular}{|l|c|c|c|c|}
\hline \multirow{2}{*}{ Confiança amostral } & \multicolumn{2}{|c|}{ Confiança estimada pelo modelo } & \multirow{2}{*}{ Total } \\
\cline { 2 - 5 } & Razoável & Pouca & Nenhuma & \\
\hline \multirow{2}{*}{ Razoável } & $\mathbf{1 7}$ & 183 & 105 & 305 \\
\hline \multirow{2}{*}{ Pouca } & $\mathbf{4 8 , 5}$ & 23,7 & 8,8 & 15,3 \\
\hline \multirow{2}{*}{ Nenhuma } & 16 & $\mathbf{3 2 7}$ & 433 & 776 \\
\cline { 2 - 5 } & 45,7 & $\mathbf{4 2 , 3}$ & 36,5 & 38,9 \\
\hline \multirow{2}{*}{ Total } & 2 & 262 & $\mathbf{6 4 7}$ & 911 \\
\cline { 2 - 5 } & 5,71 & 33,9 & $\mathbf{5 4 , 6}$ & 45,7 \\
\hline
\end{tabular}

Fonte: Elaboração própria com base em Nupps (2014). Na segunda linha de cada grau de confiança valores percentuais. Valores em negrito indicam o contingenciamento que apresenta a maior proporção da coluna.

Em termos absolutos, as estimações do modelo sempre convergem para aquilo que foi observado no survey, isto é, sempre a maior proporção encontrada se situa nas células em que modelo e survey convergem. Na categoria nenhuma, mais de $50 \%$ dos casos foram estimados corretamente, enquanto na categoria pouca confiança isso aconteceu com $42,3 \%$ dos casos. Evidentemente isso não significa que o modelo não tenha imprecisões e limitações, é mister ainda aprimorá-lo para mitigar vieses ocultos ou das próprias variáveis usadas. Contudo, à luz da literatura, aponta-se para a necessidade de encontrar outros fatores que afetariam essa atitude, já que os outros argumentos elencados pela área se mostraram insignificantes, ao menos no caso brasileiro. Por ora, defende-se que este seja um modelo adequado para acessar a confiança em partidos políticos no Brasil.

Resta, enfim, avaliar os efeitos marginais das variáveis. O procedimento se deu da seguinte forma. Suponha que se deseje mensurar o efeito marginal de se ter uma avaliação de que a corrupção se manteve igual no governo de Rousseff. Nesse caso, estima-se a probabilidade de o respondente 1 ter razoável confiança em partidos políticos, por exemplo, conservando os valores das demais variáveis, conforme estes foram coletados, mas tratando como se o respondente 1 tivesse feito, de fato, essa avaliação, independentemente de qual ela seja. Em seguida, faz-se o mesmo procedimento, mas supondo que o respondente 1 não fez uma avaliação de que a corrupção ficou igual. A diferença entre essas probabilidades compõe o efeito marginal dessa variável no caso do 
respondente 1. A estratégia é repetida em todos os casos, isto é, para as 2 mil pessoas, sendo que a média dos efeitos marginais de cada caso compõe o efeito marginal da variável em questão.

\section{Tabela 4}

Efeitos marginais das variáveis independentes

\begin{tabular}{|l|c|c|c|}
\hline \multirow{2}{*}{ Variável } & \multicolumn{3}{|c|}{ Efeito marginal sobre confiança } \\
\cline { 2 - 4 } & Nenhuma & Pouca & Razoável \\
\hline Consumo JN & $-0,011$ & 0,005 & 0,006 \\
\hline Corrupção pior & 0,104 & $-0,048$ & $-0,056$ \\
\hline Corrupção igual & $-0,070$ & 0,037 & 0,032 \\
\hline Corrupção melhor & $-0,161$ & 0,075 & 0,086 \\
\hline Economia pior & 0,104 & $-0,048$ & $-0,056$ \\
\hline Economia igual & $-0,078$ & 0,041 & 0,036 \\
\hline Economia melhor & $-0,118$ & 0,059 & 0,059 \\
\hline Perdedor-não-PT & 0,145 & $-0,067$ & $-0,078$ \\
\hline Vencedor partidário & $-0,130$ & 0,060 & 0,070 \\
\hline Sem capital social & 0,247 & $-0,114$ & $-0,132$ \\
\hline Capital social & $-0,239$ & 0,111 & 0,128 \\
\hline
\end{tabular}

Fonte: Elaboração própria com base em Nupps (2014).

Conforme elucidado, a Tabela 4 apresenta esses efeitos marginais. É interessante observar, em primeiro lugar, que os efeitos marginais da variável confiança interpessoal são maiores do que os das variáveis avaliativas. Em segundo lugar, nota-se que o efeito negativo sobre a probabilidade de se ter nenhuma confiança em partidos políticos para uma avaliação positiva da economia, por exemplo, é maior do que o efeito positivo sobre a probabilidade de se ter razoável confiança, tendo a mesma avaliação.

Em outras palavras, é importante ressaltar como o efeito marginal de cada uma das variáveis diminui à medida que se estima esse efeito para os níveis superiores de confiança. O cenário aponta no sentido de que as hipóteses da literatura são, portanto, assimétricas. O termo foi explorado por Clark, Gilligan e Golder (2006), segundo os quais,

if the same change in the causally produced phenomenon is expected both when the cause is added and when it is taken away. For example, the claim that $X$ is a symmetric cause of $Y$ means that (1) if $X$ is present, $Y$ is more likely to occur (or in the continuous case, more of $X$ causes more of $Y$ ) and (2) if $X$ is absent, $Y$ is less likely to occur (or in the continuous case, less of $X$ causes less of $Y$ ). (...) In the discrete case, the claim that $X$ is an asymmetric cause of $Y$ either means ( $i$ ) that if $X$ is present, $Y$ will certainly occur, but if $X$ is absent, $Y$ may or may not occur or (ii) if $X$ is present, $Y$ may or may not occur, 
EXPLICAÇÕES ASSIMÉTRICAS PARA A DESCONFIANÇA EM PARTIDOS POLÍTICOS NO BRASIL

but if $\mathrm{X}$ is absent, $\mathrm{Y}$ will certainly not occur" (Clark, Gilligan e Golder, 2006, p. 313 , ênfase nossa).

Os efeitos assimétricos ficam ainda mais claros conforme analisamos o Gráfico 2, ou os Gráficos 3 a 5 no Anexo. Especificamente no Gráfico 2, fazemos referência à avaliação da corrupção no governo Dilma Rousseff, mas a tendência é a mesma em todos os demais. Avaliar que a corrupção nesse período melhorou registra uma probabilidade de $36 \%$ de desconfiar de partidos políticos, uma diferença de 16 pontos percentuais em relação a uma situação em que se avalia que a corrupção piorou (52\%), a diferença entre essas probabilidades no caso de razoável confiança é de 9 pontos percentuais $(20 \%$ e $11 \%$, respectivamente).

\section{Gráfico 2}

Probabilidades dos níveis de confiança - Avaliação da evolução da corrupção no governo Dilma Rousseff

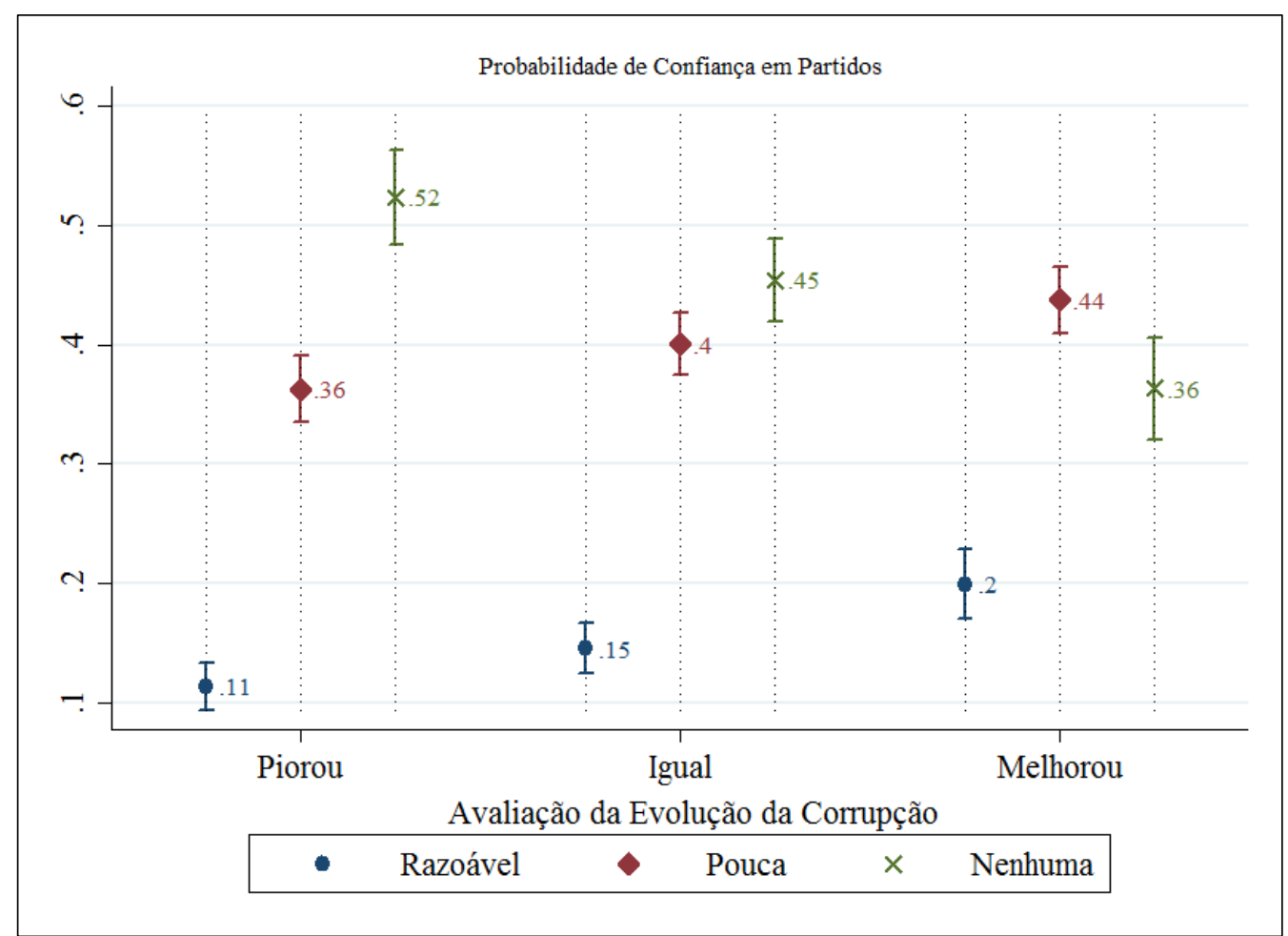

Fonte: Elaboração própria com base em Nupps (2014).

Os resultados assinalam que esses fatores podem, isoladamente, até mitigar a desconfiança, mas não geram, necessariamente, confiança nas mesmas proporções. É digno de nota que isso também não significa que as diferentes categorias da variável dependente sejam independentes entre si, apenas que a confiança é menos sensível aos 
condicionantes elencados pela literatura do que a desconfiança, demandando uma reflexão para que encontremos explicações para tal cenário.

Argumenta-se que os efeitos assimétricos revelados empiricamente, em que a diminuição da desconfiança não é acompanhada, necessariamente, do aumento da confiança nas mesmas proporções, permitem refletir sobre uma diferença conceitual entre desconfiança e confiança, em que a primeira poderia ser um proxy para a rejeição a essas instituições, mais suscetível a variações num pequeno intervalo de tempo - próximo ao conceito de apoio específico de Easton (1975) - e a segunda, uma medida mais estável ao longo do tempo, próxima à noção de apoio difuso (Easton, 1975), em que, para que partidos tenham altos índices de confiança, faz-se necessário um entendimento diferente do que essas instituições representam ou inspiram culturalmente.

\section{Considerações finais}

Pode-se afirmar que os brasileiros não confiam em partidos políticos, e isso não tem relação com o fato de pertencerem a um determinado grupo; gênero, renda, escolaridade e idade não afetam a desconfiança que eles têm nessas instituições, a desconfiança é generalizada. Por que, então, os brasileiros não confiam em partidos políticos?

A resposta recorre a argumentos inseridos em modelos tanto racionalistas quanto culturalistas. Por um lado, os brasileiros não confiam em partidos políticos pela avaliação que fazem da corrupção - indicador para a hipótese procedimental - e da economia. No caso, avaliar que a corrupção aumentou ou piorou engendra uma maior desconfiança em partidos.

À luz do trabalho de Sztompka (1999), diz-se que os partidos quebram as expectativas instrumentais que os cidadãos têm dessas instituições. Espera-se que estas sejam eficientes e competentes, que cumpram suas funções com diligência, o que cria, por conseguinte, desapontamento e hostilidade ante as instituições representativas quando se avalia que elas não foram capazes de entregar um resultado econômico satisfatório ou que se comportaram de maneira corrupta.

Nesse caso, a associação entre identificação com o então incumbente do Executivo nacional e menores níveis de desconfiança pode ser vista como uma espécie de medida indireta de avaliação de sua performance e, consequentemente, de sua confiabilidade, ou seja, a simpatia com o partido incumbente enviesa positivamente a avaliação que se faz da performance do regime, aumentando sua confiança nos partidos políticos.

No entanto, além de expor os fatores que estão associados à desconfiança no Brasil, este artigo buscou mensurar os efeitos que esses fatores provocavam sobre a desconfiança e a confiança em partidos. A demonstração de que os fatores supracitados são assimétricos indica caminhos futuros para a análise dos condicionantes dessa atitude no país, sob a perspectiva teórica. Em primeiro lugar, dá a entender que os tradicionais responsáveis elencados pela literatura não dão conta de revelar mecanismos que criariam 
confiança entre as entidades em foco nesta análise, extrapolando o efeito mitigador de uma avaliação positiva sobre a desconfiança. Nada indica que esses dois caminhos - o crescimento da confiança e a diminuição da desconfiança - estejam deterministicamente associados, isto é, a queda de um não implicaria, necessariamente, o crescimento do outro.

Em segundo lugar, argumenta-se que os efeitos assimétricos criam condições para refletir sobre diferenças conceituais entre desconfiança e confiança em partidos no Brasil. Em que pese a evidente proximidade dessas categorias, a desconfiança generalizada empresta a essa atitude um tom de hostilidade diante de partidos políticos, algo expressado, por exemplo, na aversão a partidos políticos nas manifestações que se desenrolaram, sobretudo, a partir de junho de 2013.

Desconfiança poderia ser entendida como a extensão da hostilidade que partidos enfrentam na sociedade num determinado momento, podendo ser mitigada a partir de uma avaliação positiva de sua performance, um indicador momentâneo do apoio que os partidos angariam na sociedade, sendo uma espécie de apoio específico. Ao passo que a confiança em partidos seria vista como a perspectiva culturalmente estabelecida dessas instituições, semelhante ao apoio difuso de Easton (1975).

Obviamente essas categorias não são independentes entre si, mas seus comportamentos diferentes ante os fatores que as impactam, em que a confiança terá um espaço muito menor para crescer, indicam um tipo de antipartidarismo cultural, mais profundo na sociedade, em que sua reprodução é ritualizada, enquanto a desconfiança remeteria a um antipartidarismo reativo ${ }^{9}$.

A extensão desse antipartidarismo cultural e a assimetria dessas variáveis fornecem indícios da consagração de uma cultura de baixa confiança em partidos (Sztompka, 1999). Assim, a avaliação que se faz dos partidos, em vez de partir da premissa de que estes levam em conta, ao fim e ao cabo, os interesses dos representados, pressupõe que eles agem independentemente dos interesses daqueles que eles representam.

Once the decay of trust reaches this cultural level, distrust becomes contagious and self-enhancing. From now on it is a "normal", accepted reaction to be distrustful, and all displays of trust are considered as signs of credulity, naivety, and simple-mindedness, and meet with ridicule, mockery, and other negative sanctions. Sadly and paradoxically, cynicism has been raised to a virtue (Sztompka, 1999, p. 174).

É como se a premissa normativamente associada a essas instituições fosse, justamente, a frustração das expectativas da população, ou ainda, a convicção de que essas instituições não são dignas de confiança, de modo algum. Cria-se um argumento tautológico que consagra a cultura de baixa confiança: brasileiros não confiam em partidos

\footnotetext{
9 Esses termos são extraídos de Torcal, Gunther e Montero (2002), mas operacionalizados de maneira distinta.
} 
políticos, pois estes não inspiram confiança. Tornou-se prudente, consensual ou inevitável desconfiar de partidos políticos.

Resolver a questão de ser positivo ou negativo esse cenário para a democracia brasileira não é o objetivo deste artigo. Da mesma maneira que é possível afirmar que a desconfiança pode fomentar a hostilidade e o distanciamento entre partidos e eleitores, pode-se argumentar que a grande desconfiança exige monitoramento por parte dos eleitores e participação para constranger partidos. Acredita-se apenas que o presente artigo traz elementos que incentivam a reflexão acerca das dinâmicas da representação no Brasil, levando a uma maior compreensão do que as afetaria.

Eduardo Alves Lazzari - Doutorando no Departamento de Ciência Política, Faculdade de Filosofia, Letras e Ciências Humanas, Universidade de São Paulo. E-mail: <eduardo.lazz@hotmail.com>.

\section{Referências bibliográficas}

BLOOM, H.; PRICE, D. "Voter response to short-run economic conditions: the asymmetric effect of prosperity and recession". The American Political Science Review, Cambridge, vol. 69, n 4, p. $1.240-1.254,1975$.

Booth, J.; Seligson, M. The legitimacy puzzle in Latin America: political support and democracy in eight nations. Cambridge: Cambridge University Press, 2009.

CARneIRo, G.; MoIsÉS, J. "Sobre o enraizamento dos partidos políticos na sociedade brasileira". Interesse Nacional, ano 7, no 28, 2015.

ChaiA, V.; TeiXeirA, M. "Democracia e escândalos políticos". São Paulo em Perspectiva, São Paulo, vol. 15, n० $4,2001$.

ClAGget, W. "A reexamination of the asymmetry hypothesis: economic expansions, contractions and congressional elections". The Western Political Quarterly, Salt Lake City, vol. 39, n 4, p. 623-633, 1986.

Clark, W.; Gilligan, M.; Golder, M. "A simple multivariate test for asymmetric hypothesis". Political Analysis, Oxford, vol. 14, p. 311-331, 2006.

DALton, R.; WATtenberg, M. Parties without partisans: political change in advanced industrial societies. Oxford: Oxford University Press, 2000.

Duch, R.; SteVenson, R. The economic vote: how political and economic institutions condition election results. Cambridge: Cambridge University Press, 2008.

EASTON, D. "A re-assessment of the concept of political support". British Journal of Political Science. Cambridge, vol. 5, n०4, p. 435-457, 1975.

HARDIN, R. Do we want trust in government?. In: WARREN, M. (ed.). Democracy and trust. Cambridge: Cambridge University Press, 1999. 
EXPLICAÇÕES ASSIMÉTRICAS PARA A DESCONFIANÇA EM PARTIDOS POLÍTICOS NO BRASIL

Inglehart, R.; Flanagan, S. "Value change in industrial societies". The American Political Science Review, Cambridge, vol. 81, no 4, p. 1.289-1.319, 1987.

KATZ, R.; MAIR, P. How parties organize: change and adaptation in party organizations in Western democracies. Londres: Sage Publications, 1994.

KInzo, M. Representação política e sistema eleitoral no Brasil. São Paulo: Edições Símbolo, 1980.

Lavalle, A.; Houtzager, P.; CASTello, G. "Democracia, pluralização da representação e sociedade civil". Lua Nova, São Paulo, n 67, p. 49-103, 2006.

LiJPhART, A. Modelos de democracia. São Paulo: Civilização Brasileira, 2003.

MANIN, B. The principles of representative government. Cambridge: Cambridge University Press, 1995.

MAnin, B.; Przeworski, A.; Stokes, S. "Eleições e representação". Lua Nova, São Paulo, nº 67, p. $105-138,2006$.

MESQUITA, N. Jornal Nacional, democracia e confiança nas instituições democráticas. In: MoISÉs, J. (ed.). Democracia e confiança: por que os cidadãos desconfiam das instituições públicas? São Paulo: Edusp, 2010.

. Mídia e apoio político à democracia no Brasil. In: Moisés, J .; Meneguello, R. (eds.). $A$ desconfiança política e os seus impactos na qualidade da democracia. São Paulo: Edusp, 2013.

MILL, J. S. Considerações sobre o governo representativo. São Paulo: Escala, 2006.

Moisés, J.; Meneguello, R. (eds.). A desconfiança política e os seus impactos na qualidade da democracia. São Paulo: Edusp, 2013.

NORRIS, P. Critical citizens: global support for democratic governance. Oxford: Oxford University Press, 1999.

2011.

Democratic deficit: critical citizens revisited. New York: Cambridge University Press,

Nupps/usp. Brasil, 25 anos de democracia - balanço crítico: políticas públicas, instituições, sociedade civil e cultura política. São Paulo: Universidade de São Paulo, 2014.

PITKIN, H. The concept of representation. Berkeley: University of California Press, 1972.

Porto, M. "La crisis de confianza en la política y sus instituciones: los medios y la legitimidade de la democracia en Brasil". América Latina Hoy, Salamanca, no 25, 2000.

Putnam, R. "Tuning in, tuning out: the strange disappearance of social capital in America". Political Studies and Politics, Cambridge, vol. 28, n 4, p. 664-683, 1995.

SzTompKA, P. Trust: a sociological theory. Cambridge: Cambridge University Press, 1999.

TORCAL, M.; GUnther, R.; MONTero, J. Anti-party sentiments in Southern Europe. In: Gunther, R.; Montero, J. R.; Linz, J. J. (eds.). Political parties: old concepts and new challenges. Oxford: Oxford University Press, 2002. 
EDUARDO ALVES LAZZARI

URBinATI, N. "O que torna a representação democrática?". Lua Nova, São Paulo, n 67, p. 191-228, 2006.

WhitTen, G.; PALMER, H. "Heightening 'comparativists' concern for model choice: voting behavior in Great Britain and the Netherlands". American Journal of Political Science, East Lansing, vol. 40, n 1, p. 231-260, 1996.

\section{Anexo}

\section{Gráfico 3}

\section{Probabilidades dos níveis de confiança - Avaliação} da economia no governo Rousseff

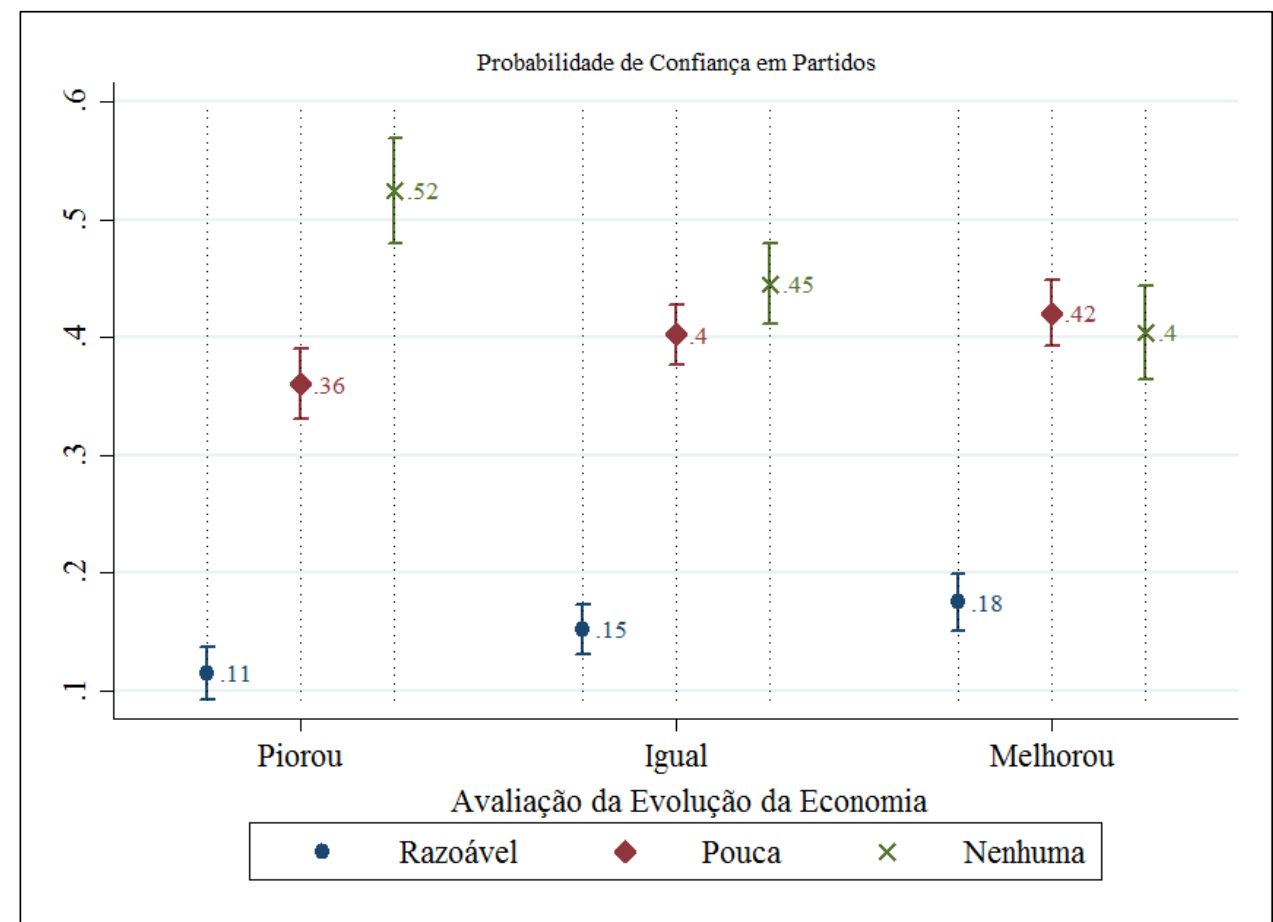

Fonte: Elaboração própria com base em Nupps (2014) 
EXPLICAÇÕES ASSIMÉTRICAS PARA A DESCONFIANÇA EM PARTIDOS POLÍTICOS NO BRASIL

\section{Gráfico 4}

Probabilidades dos níveis de confiança - Identificação com o PT

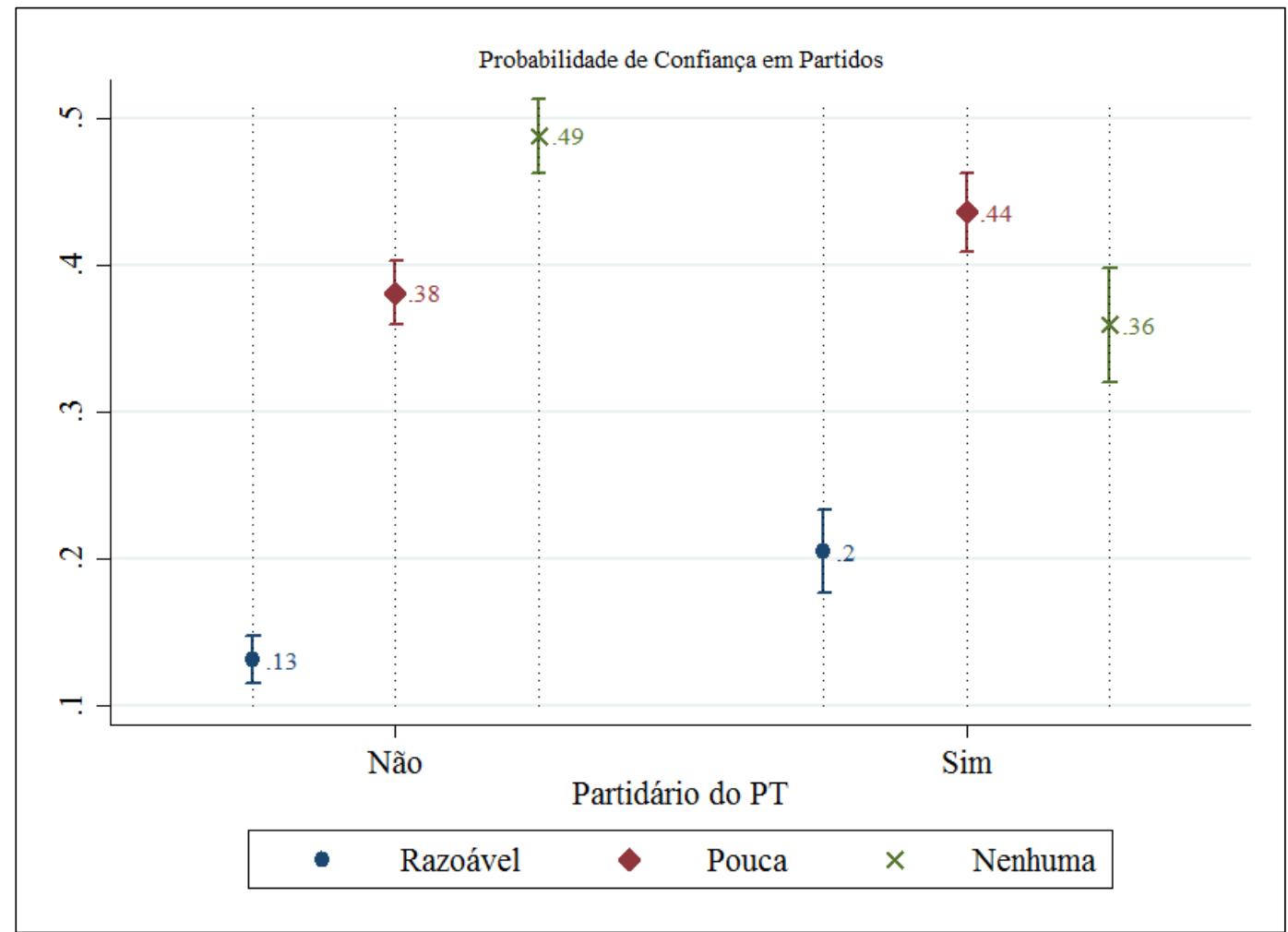

Fonte: Elaboração própria com base em Nupps (2014). 


\section{Gráfico 5}

Probabilidades dos níveis de confiança - Confiança Interpessoal

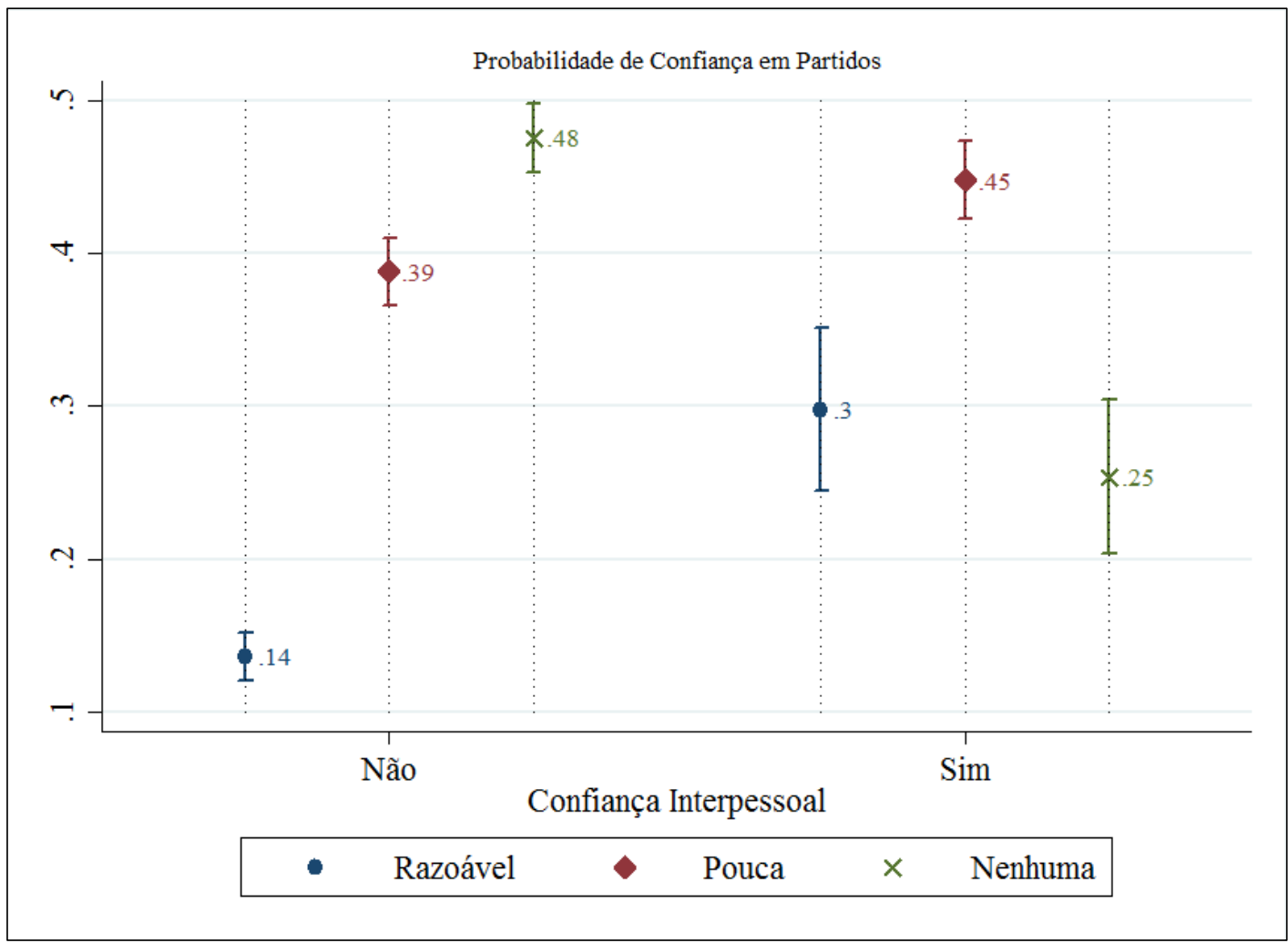

Fonte: Elaboração própria com base em Nupps (2014).

\section{Resumo}

Explicações assimétricas para a desconfiança em partidos políticos no Brasil

Por que os brasileiros não confiam em partidos políticos? Essa é a pergunta-chave deste artigo. Analisa-se essa pergunta com a mobilização de hipóteses da área, englobando argumentos racionalistas e culturalistas. Para respondê-la, utiliza-se de survey representativo da população brasileira e conduzido pelo Nupps/USP em 2014, em que regressões logísticas ordinais são executadas. Os resultados mostram, em primeiro lugar, que hipóteses avaliativas e a confiança interpessoal são os condicionantes dessa atitude no país. Em segundo lugar, observa-se que os efeitos dessas hipóteses são assimétricos, levando a uma reflexão acerca das diferenças conceituais entre desconfiança e confiança em partidos no Brasil para um melhor entendimento das dinâmicas da representação no país.

Palavras-chave: confiança; partidos políticos; Brasil 


\begin{abstract}
Asymmetric explanations for the distrust in political parties in Brazil

Why do Brazilians not trust political parties? This is the key question of this article. This work first analyzes the question by mobilizing the hypotheses advanced in the literature, comprehending rationalist and culturalist arguments. To answer it, we use data from a representative survey in Brazil conducted by Nupps/USP in 2014, executing ordinal logistic regressions. The results show, first, that evaluative hypotheses and interpersonal trust are the determinants of this attitude in the country and, second, that the effects of these hypotheses are asymmetrical, leading to remarks about the conceptual differences between distrust and trust in political parties in Brazil, promoting a better understanding of the dynamics of representation in the country.
\end{abstract}

Keywords: trust; political parties; Brazil

\title{
Resumen
}

Explicaciones asimétricas para la desconfianza en partidos políticos en Brasil

¿Por qué los brasileños no confían en los partidos políticos? Esta es la pregunta clave en este artículo. Se analiza esta pregunta utilizando las hipótesis de la literatura, articulando argumentos racionalistas e culturalistas. Para responder a esto, los datos utilizados son los resultados de una encuesta representativa de la población brasileña y conducida por NUPPS/USP en 2014, donde regresiones logísticas ordinales son ejecutadas. Los resultados muestran, en primer lugar, que hipótesis evaluativas y la confianza interpersonal son condicionantes de esta actitud en el país. En segundo lugar, es posible observar que los efectos de estas hipótesis son asimétricos, llevando a reflexiones sobre diferencias conceptuales entre la desconfianza y confianza en los partidos políticos en Brasil, para una mejor comprensión de las dinámicas representativas en el país.

Palabras clave: confianza; partidos políticos; Brasil

\section{Résumé}

Explications asymétriques de la méfiance à l'égard des partis politiques au Brésil

Pourquoi les Brésiliens ne font-ils pas confiance aux partis politiques ? C'est la question clé de cet article. On analyse cette question en mobilisant des hypothèses de la littérature, y compris des arguments rationalistes et culturalistes. Pour y répondre, on utilise les données d'une enquête menée par NUPPS/USP en 2014, sur un échantillon représentatif de la population brésilienne, en utilisant des régressions logistiques ordinales. En premier lieu, les résultats montrent que des hypothèses évaluatives et la confiance interpersonnelle sont les déterminants de cette attitude dans le pays. En second lieu, on observe que ces effets sont asymétriques, ouvrant la réflexion sur les différences conceptuelles entre méfiance et confiance envers les partis politiques au Brésil, afin de mieux comprendre la dynamique de représentation dans le pays.

Mots-clés: confiance; partis politiques; Brésil 